\title{
Analysis of Rhodopsin G Protein-Coupled Receptor Orthologs Reveals Semiochemical Peptides for Parasite (Schistosoma Mansoni) and Host (Biomphalaria Glabrata) Interplay
}

Phong Phan ( $\nabla$ tuanphong.phan@research.usc.edu.au )

University of the Sunshine Coast

Di Liang

University of the Sunshine Coast

Min Zhao

University of the Sunshine Coast

Russell C. Wyeth

St. Francis Xavier University

Conor Fogarty

University of the Sunshine Coast

Mary G. Duke

QIMR Berghofer Medical Research Institute

Donald P. McManus

QIMR Berghofer Medical Research Institute

Tianfang Wang

University of the Sunshine Coast

Scott F. Cummins

University of the Sunshine Coast

\section{Research Article}

Keywords: Biomphalaria glabrata, Schistosoma mansoni, schistosome, rhodopsin GPCRs, buccalin, FMRFamide

Posted Date: February 21st, 2022

DOI: https://doi.org/10.21203/rs.3.rs-1194469/v2

License: (9) This work is licensed under a Creative Commons Attribution 4.0 International License. Read Full License 


\section{Abstract}

Background: Schistosomiasis is a medically significant disease caused by helminth parasites of the genus Schistosoma. The schistosome life cycle requires chemically mediated interactions with an intermediate (aquatic snail) and definitive (human) host. Blocking parasite development within the snail stage requires improved understanding of the interactions between the snail host and the Schistosoma water-borne free-living form (miracidium). Innovations in snail genomics and aquatic chemical communication provide an ideal opportunity to explore snail-parasite coevolution at the molecular level. Rhodopsin G protein-coupled receptors (GPCRs) are of particular interest in studying how trematode parasites navigate towards their snail hosts. The potential role of GPCRs in parasites makes them candidate targets for new antihelminthics that disrupt the intermediate host life-cycle stages, thus preventing subsequent human infections.

Results: A genomic-bioinformatic approach was used to identify GPCR orthologs between the snail Biomphalaria glabrata and miracidia of its obligate parasite Schistosoma mansoni. We show that 8 S. mansoni rhodopsin GPCRs expressed within the miracidial stage share overall amino acid similarity with 8 different $B$. glabrata rhodopsin GPCRs, particularly within transmembrane domains, suggesting conserved structural features. These GPCRs include an orphan peptide receptor as well as several with strong sequence homologies with rhabdomeric opsin receptors, a serotonin receptor, a sulfakinin (SK) receptor, an allatostatin-A (buccalin) receptor and an FMRFamide receptor. Buccalin and FMRFa peptides were identified in water conditioned by $B$. glabrata, and we show synthetic buccalin and FMRFa can stimulate significant rates of change of direction and turn-back responses in $S$. mansoni miracidia.

Conclusions: Ortholog GPCRs were identified in S. mansoni miracidia and B. glabrata. These GPCRs may detect similar ligands, including snail-derived odorants that could facilitate miracidial host finding. These results lay the foundation for future research elucidating the mechanisms by which GPCRs mediate host finding which can lead to the potential development of novel anti-schistosome interventions.

\section{Introduction}

Metazoan helminth blood flukes of the genus Schistosoma are the primary etiological agents of human schistosomiasis, a disease endemic in 74 countries that affects over 200 million people worldwide [1]. Globally, up to 200,000 people die directly or indirectly due to schistosomiasis annually [2] and an estimated 600 million people live in endemic areas [3]. Schistosomes have a complex dioecious life cycle, involving asexually reproduced larvae in a molluscan intermediate host and sexually reproductive adult worms in the mammalian definitive host. In water, Schistosoma mansoni eggs hatch into free-living, mobile miracidia that must search and infect a compatible snail host, Biomphalaria glabrata [4]. Following infection, a single miracidium can reproduce asexually via mother and daughter sporocysts, into several thousand cercariae that each when released may develop into an adult worm in the human host. The complex physiological and morphological changes associated with the Schistosoma life-cycle means that the anthropogenic control of transmission could be directed at several life cycle stages. 
Currently, the adult worms are usually targeted through treatment of infected humans with the drug praziquantel [5]. Nevertheless, the disease remains a constant threat in developing countries and the World Health Organization has acknowledged that continued research on the snail infection stage is required [6]. For example, alternative methods of interfering with the Schistosome life-cycle could involve the application of anthelmintic drugs that target the host seeking behavior of miracidia or cercariae $[7,8]$.

Schistosome miracidia have restricted vision and limited time (12-16 hours) to find an appropriate host snail [9]. Host identification involves a range of behavioral responses that promote host localization, thereby increasing the likelihood of successful infection $[10,11]$. Sharing the same living environment with the intermediate host makes the miracidial stage an ideal point to interrupt the parasite's life cycle and represents a target window for assessing the molecular components required for host finding. Two main behavioural responses occur comprising an initial dispersal and directional phase influenced by photoreceptor mediation, and a secondary seeking and circling phase (chemokinesis) that is olfactorymediated [7, 12-14]. To date, little information is available concerning the underlying molecular mechanisms that dictate olfactory-mediated host detection by schistosome miracidia although a peptide was recently discovered from $B$. glabrata that induces behavioural changes in miracidia [15].

G protein-coupled receptors (GPCRs) are well recognized as chemosensory receptors in eumetazoans [16], and are a promising research focus for understanding parasite host-finding. GPCRs and downstream biochemical pathways are often used as selective pharmacological targets for parasite lifecycle interruption $[17,18]$, and thus may be effective targets for miracidial manipulation. At the molecular level, there are some reports on $S$. mansoni receptor biology and signal transduction pathways such as the discovery of an array of genome-encoded sensory-type proteins $[19,20]$. These include GPCRs [21] that may interact with chemical ligands, a concept supported by proteomic and functional expression analyses that identified GPCRs in the miracidia and adult tegumental matrix of schistosomes [11, 22, 23]. Scrutiny of the $S$. mansoni genome revealed numerous rhodopsin-type GPCR sequences using a combination of three bioinformatic algorithms, including the Phobius, HMMerSearch and Pfam scan [24, 25]. Those expressed in the miracidia included two opsin receptors, which may underpin miracidial photokinetic behavior [26, 27].

Emerging information shows that the close association of the snail and its obligate schistosome parasite has helped in shaping their respective genomes. The genetic variability of the snail host, rather than the human host, may be a more significant factor in influencing the variability of life history traits in schistosomes [28-30]. For example, it has been noted that the presence of homologous mucin proteins between the snail and different strains of $S$. mansoni may be key elements underlying snail host-parasite compatibility [31]. This is consistent with the discovery of significant homology of the non-coding 5 ' and 3 regions of non-long terminal repeat retrotransposon nimbus sequences; these class I transposable elements copy and paste themselves into different genomic location, in the host and parasite, suggesting possible horizontal transfer of host sequences into the parasite [32, 33]. 
In this study, we identified $S$. mansoni miracidia rhodopsin-like GPCRs that share significant sequence identity with rhodopsin-like GPCRs in B. glabrata. This new knowledge guided peptide behaviour bioassays on $S$. mansoni miracidia which demonstrated that FMRFa and buccalin peptides can elicit behaviours consistent with host finding.

\section{Materials And Methods}

\section{S. mansoni miracidia collection and transcriptome preparation}

Livers were obtained from ARC Swiss mice infected with S. mansoni (Puerto Rican strain) under conditions specified by the Australian Department of Agriculture, Fisheries and Forestry (DAFF). Mice were euthanized with $\mathrm{CO} 2$ gas and their livers were perfused with chilled PBS. Eggs of S. mansoni were collected during perfusion of mice. Four infected mouse livers were sliced with scalpel blades and blended to a smooth consistency in $50 \mathrm{~mL}$ phosphate buffered saline (PBS). A two-day protocol was used to obtain relatively clean schistosome eggs and miracidia [34]. In brief, the mixture of eggs and mouse liver tissue were incubated with collagenase $\mathrm{B}$, penicillin and streptomycin at $37^{\circ} \mathrm{C}$ overnight, followed by fractionation using Percoll columns ( $8 \mathrm{ml}$ Percoll $+32 \mathrm{ml}$ of $0.25 \mathrm{M}$ sucrose in $50 \mathrm{ml}$ tubes). The egg pellets were washed using PBS twice on a second Percoll column $(2.5 \mathrm{ml}$ Percoll $+7.5 \mathrm{ml} 0.25 \mathrm{M}$ sucrose in a $15 \mathrm{ml}$ tube). Purified eggs were transferred into a $200 \mathrm{ml}$ hatching measuring cylinder wrapped completely in light-blocking black tape with the exclusion of the top $4 \mathrm{~cm}$ from the lip, thereby producing a light-gradient. The hatching cylinder was topped with $\mathrm{pH}$ neutral MilliQ water until $1.5 \mathrm{~cm}$ above the tape-covered area and exposed to bright light at $27^{\circ} \mathrm{C}$. Eggs were incubated for $6 \mathrm{~h}$ post-hatch, and the top $10 \mathrm{ml}$ of miracidium-containing water was collected for miracidia isolation. Hatched miracidia were isolated by centrifugation at $8,000 \times \mathrm{g}$ for $1 \mathrm{~min}$ at $4^{\circ} \mathrm{C}$, and washed twice with water. For RNA isolation, miracidia were collected at $6 \mathrm{~h}$ post-hatch and kept at $-80^{\circ} \mathrm{C}$. Total RNA was isolated from S. mansoni miracidia ( $6 \mathrm{~h}$ post-hatch in triplicate) using TRIzol reagent following the manufacturer's user guide (Invitrogen, USA), the RNA quantity and quality were assessed by UV spectrophotometry (NanoDrop ND-1000) and the RNA was sent to NovoGene (Hongkong) for next-generation Illumina 2500 platform RNA-seq. Raw sequence data was deposit into the GenBank NCBI under accession number SRR17224866. De novo transcriptome assembly of the $S$. mansoni miracidia raw sequence data was performed using Trinity, as previously described $[35,36]$ and contigs were translated into protein sequences using Transdecoder [35]. Gene expression levels of the $S$. mansoni miracida were calculated by mapping raw sequence data against the $S$. mansoni reference genome derived from WormBase Parasite (https://parasite.wormbase.org/Schistosoma_mansoni_prjea36577/Info/Index/) using CLC Genomic Workbench with default parameters [37].

\section{Gene identification and functional annotation}

The pipeline for identification of ortholog GPCRs shared between B. glabrata and S. mansoni is shown in Figure 1. For B. glabrata, data on GPCRs and their expression levels in different tissues were retrieved 
from a previous study [6]. With S. mansoni, transcriptome-derived protein sequences were searched for Pfam-based profiles and TM domains to identify receptors that belong to the rhodopsin GPCR family. Specifically, this included two bioinformatic tools to predict TM domains for all proteins, including TMHMM (http://www.cbs.dtu.dk/services/TMHMM-2.0/) and Phobius (http://phobius.sbc.su.se/). As TM domains are convenient markers for GPCRs, we only focused on those sequences with 7-TM domains. Next, we applied a Pfam-based profile search using HMMerSearch (http://www.hmmer.wustl.edu/). Proteins containing putative rhodopsin-type GPCR domains were systematically identified by profile hidden Markov model searches using the HMMer package (http://www.hmmer.wustl.edu/) and the PFAM model PF00001 (7tm_1).

Putative GPCRs identified in S. mansoni miracidia were used to query (using tBLASTp) the B. glabrata GPCR database. Those sequences with E-values $<1.0 \mathrm{E}-20$ were retrieved and screened for the presence of recurrent transmembrane motifs using TMHMM (http://www.cbs.dtu.dk/services/TMHMM/). Those containing 7 transmembrane (TM) domains were selected for further analysis. Multiple sequence alignments were created with Molecular Evolutionary Genetics Analysis (MEGA) software version 6.0 [38] with the MUSCLE [39] algorithm. Phylogenetic trees were constructed using the neighbor-joining method with 1000 bootstrap replicates for node support. Gene ontology mapping and functional annotation were applied by using OmicsBox (BioBam) [40]. The final phylogenetic tree and heatmap were modified with iTOL v5 [41].

\section{Miracidia behaviour in response to test solutions}

Test solutions: Synthetic FMRFa (FMRF-NH ${ }_{2}$ ), buccalin (RLDRFGFAGQL-NH ${ }_{2}$ ) and SK (KRQGAWSYDYGLGGGRFGKRNYGDYGIGGGRFGR) were provided by China Peptides (Shanghai, China) (purity $\geq 95 \%$ ). Serotonin (5-hydroxytryptamine/5-HT) was provided by Sigma (Burlington, United States) (purity $\geq 98 \%)$. Stock solutions of FMRFa $(100 \mu \mathrm{M})$, buccalin $(100 \mu \mathrm{M})$, SK $(100 \mu \mathrm{M})$ and 5 -HT $(5 \mathrm{mM})$ were prepared by dissolving in MilliQ water. MilliQ water was used as a negative control in bioassays.

\section{Miracidia collection and assay}

Isolation of $S$. mansoni miracidia at $\sim 2 \mathrm{~h}$ post-hatch was performed as described in Wang et al [21]. For each assay, $30 \pm 5$ actively swimming miracidia in $\mathrm{pH}$ neutral MilliQ water ( $\sim \mathrm{ml}$ in total) were evenly distributed with a pipette to the central region of a Petri dish $(100 \mathrm{~mm} \times 15 \mathrm{~mm})$ containing $4 \mathrm{ml}$ of MilliQ water. The swimming area for the miracidia was covered to prevent light bias prior to analysis under the microscope. For assays, $2 \mu \mathrm{l}$ of test solution were added to the central area of the Petri dish. Some diffusion of each molecule was expected over the 1 min test period. Assays were also tested at 10x and $100 \times$ serial dilutions. To record miracidia movement before and after addition of the test solutions, an inverted compound microscope with videoing capacity (OLYMPUS CKX41), fitted with an OLMPUS DPI Digital Microscope Camera DP22 (2.8-megapixel image at a rate of 15 frames per second), was used. The real camera's field of view (FOV) was $2.500 \times 1.875 \mathrm{~mm}$. Miracidia movement was recorded for $1 \mathrm{~min}$ 
before and after the addition of each test solution and captured videos were processed using Tracker 4.87 .

\section{Analysis}

Miracidia trajectories were tracked manually from entrance into the FOV to exit, or up to $1 \mathrm{~min}$ for those that remained within the FOV. Only miracidia that had been swimming for more than the length of the short edge $(7.5 \mathrm{~cm})$ of the FOV were included before and after solution addition; those that did not were considered statistically meaningless. The average time duration of miracidia staying within the FOV was considered as another key behavioural feature and was statistically compared. For those miracidia staying for more than $1 \mathrm{~min}$ after addition of solution, the time duration within that $1 \mathrm{~min}$ was used for comparison, and the mean acceleration value was calculated. Miracidium acceleration and velocity were calculated based on trajectories, with units converted to $\mathrm{cm} \mathrm{s}^{-2}$ and $\mathrm{cm} / \mathrm{s}$. A paired two-tailed t-test was used to calculate $P$-values; in addition, wherever applicable, two-way ANOVA analysis [42] was performed to evaluate the significance of changes (acceleration, velocity and time) among the test solutions and the negative control.

Isolation of B. glabrata - conditioned water extract and dot blot assay

B. glabrata were washed with $\mathrm{pH}$ neutral MilliQ water and placed in beakers containing $20 \mathrm{ml}$ water for 2 $\mathrm{h}$ at room temperature (RT). Snails were removed, conditioned water was collected from 20 snails (in different aquaria), and $20 \mathrm{ml}$ methanol was added to each beaker and mixed thoroughly. The conditioned water was filtered through PVDF Millex-HV syringe filter units $(0.45 \mu \mathrm{m})$ to remove particles and microbes. The filtrate was snap frozen and lyophilized. When required for dot bot assay, samples were rehydrated with $200 \mu \mathrm{l}$ MilliQ water and centrifuged at 12,000 rpm for $5 \mathrm{~min}$. The supernatant was collected and diluted 1:1 in MilliQ water. Quantitation was performed using a NanoDrop 2000c UV-Vis spectrophotometer (Thermo Scientific, Waltham, U.S) at A280nm. B. glabrata extracts at $5 \mu \mathrm{g} / \mu \mathrm{l}, 500 \mathrm{ng} /$ $\mu \mathrm{l}$ and $50 \mathrm{ng} / \mu \mathrm{l}$ were applied $(2 \mu \mathrm{l})$ onto a nitrocellulose membrane $(0.45 \mu \mathrm{m}$, BioRad, Hercules, U.S $)$ that had been pre-soaked in 1x phosphate buffered saline (PBS) and air-dried at room temperature for $10 \mathrm{~min}$. The membrane was incubated in blocking buffer ( $2 \%(\mathrm{v} / \mathrm{v})$ skim milk in PBS) for $1 \mathrm{~h}$, and primary antibody was added [1:500; rabbit anti-buccalin [43], rabbit anti-FMRFa (Genscript, Piscataway, U.S), rat anti-5-HT (Sigma)] for $1 \mathrm{~h}$ at RT. Membranes were washed with PBS-Tween20 (0.1\% (v/v)) and incubated for $1 \mathrm{~h}$ at RT with secondary antibody [1:5000; anti-rabbit Ig-IR 680 (LI-COR, Lincoln, U.S) or anti-rat Ig-IR 795 (LI-COR)]. Following washes (3x, 5 min) in PBST, blots were visualized using an Odyssey CLx, LI-COR machine.

\section{Availability of data and materials}

The S. mansoni miracidial transcriptomic raw sequence data was deposit into the GenBank NCBI under accession number SRR17224866 (https://www.ncbi.nlm.nih.gov/sra/?term=SRR17224866). The $S$. mansoni reference genome is availabe from WormBase Parasite (https://parasite.wormbase.org/Schistosoma_mansoni_prjea36577/Info/Index/). The original B. glabrata 


\section{Results}

\section{Identification of ortholog GPCRs shared between B. glabrata and S. mansoni miracidia}

In total, 96 proteins with 7-TM domains were extracted from the $S$. mansoni transcriptome-derived protein models based on TMHMM prediction. Phobius prediction led to the identification of 139 proteins with 7TM domains. Pfam profiling of both predictions led to the classification of 87 proteins (E-value $<0.0004)$ as rhodopsin-type receptors. BLASTp analysis of these GPCRs against all B. glabrata rhodopsin GPCRs showed significant matches (E-value $<1.0 \mathrm{E}-20$ ) for 8 GPCRs (Table 1), with between 26-48\% amino acid identity (File S1a). BLASTp searches using all S. mansoni and B. glabrata ortholog GPCRs against the NCBI non-redundant (nr) database returned best match hits for GPCRs, including 5-HT (serotonin), allatostatin-type A (AST-A), FMRFa, SK, orexin type 2, neuropeptide F, orphan peptide and opsin-like GPCRs (Table 1, Fig. 2A and File S1b). In B. glabrata, all GPCRs were expressed in the CNS, while the orphan rhodopsin GPCR had the widest tissue distribution (Fig. 2B). In S. mansoni miracidia, the rhodpopsin GPCR ortholog was found to show the highest average level of expression, compared to other receptors (Fig. 2B). 
Table 1

Comparative sequence identity between Biomphalaria glabrata and Schistosoma mansoni GPCR homologs.

\begin{tabular}{|c|c|c|c|c|c|}
\hline $\begin{array}{l}\text { S. mansoni } \\
\text { ID }\end{array}$ & $\begin{array}{l}\text { B. glabrata } \\
\text { ID }\end{array}$ & $\begin{array}{l}\text { E- } \\
\text { value }\end{array}$ & $\begin{array}{l}\text { Overall } \\
\text { identity } \\
\text { (\%) }\end{array}$ & TM number (\% identity) & $\begin{array}{l}\text { Best match } \\
\text { GPCR }\end{array}$ \\
\hline Smp_140620 & BGLB028445 & $\begin{array}{l}2.78 \mathrm{E}- \\
50\end{array}$ & 26.8 & $\begin{array}{l}1(45.5), 2(64.0), 3(58.3), 4 \\
(40.0), 5(39.1), 6(45.8), 7 \\
(63.2)\end{array}$ & FMRFa \\
\hline Smp_131980 & BGLB002561 & $\begin{array}{l}2.88 \mathrm{E}- \\
42\end{array}$ & 30.5 & $\begin{array}{l}1(40.0), 2(40.0), 3(76.2), 4 \\
(50.0), 5(68.4), 6(70.8), 7 \\
(69.6)\end{array}$ & Orexin type 2 \\
\hline Smp_173010 & BGLB013427 & $\begin{array}{l}2.67 \mathrm{E}- \\
23\end{array}$ & 48.5 & $\begin{array}{l}1(45.6), 2(60.0), 3(45.8), 4 \\
(52.0), 5(39.1), 6(50.0), 7 \\
(63.2)\end{array}$ & Sulfakinin \\
\hline Smp_007070 & BGLB003586 & $\begin{array}{l}2.69 \mathrm{E}- \\
60\end{array}$ & 31.2 & $\begin{array}{l}1(29.2), 2(41.7), 3(42.9), 4 \\
(27.8), 5(36.8), 6(56.5), 7 \\
(60.9)\end{array}$ & $\begin{array}{l}\text { Neuropeptide } \\
\text { F }\end{array}$ \\
\hline Smp_126730 & BGLB013877 & $\begin{array}{l}9.83 \mathrm{E}- \\
37\end{array}$ & 34.5 & $\begin{array}{l}1(27.3), 2(26.1), 3(61.9), 4 \\
(66.7), 5(34.8), 6(60.9), 7 \\
(60.9)\end{array}$ & Serotonin \\
\hline Smp_180030 & BGLB032600 & $\begin{array}{l}4.18 \mathrm{E}- \\
20\end{array}$ & 24.9 & $\begin{array}{l}1(52.2), 2(68.2), 3(74.9), 4 \\
(52.6), 5(38.1), 6(66.7), 7 \\
(85.0)\end{array}$ & Opsin \\
\hline Smp_203500 & BGLB004467 & $\begin{array}{l}2.08 \mathrm{E}- \\
44\end{array}$ & 30.1 & $\begin{array}{l}1(47.8), 2(34.8), 3(37.0), 4 \\
(34.8), 5(47.6), 6(62.5), 7 \\
(58.3)\end{array}$ & $\begin{array}{l}\text { Allatostatin } \\
\text { A/buccalin }\end{array}$ \\
\hline Smp_049330 & BGLB001538 & $\begin{array}{l}1.44 \mathrm{E}- \\
59\end{array}$ & 36.8 & $\begin{array}{l}1(42.8), 2(54.1), 3(32.8), 4 \\
(39.4), 5(41.6), 6(64.5), 7 \\
(54.7)\end{array}$ & Rhodopsin \\
\hline
\end{tabular}

\section{Bioassay of peptides on S. mansoni miracidia behaviour}

The elucidation of interspecies GPCR orthologs with putative ligands presented an opportunity to investigate how snail-derived biomolecules influence $S$. mansoni miracidia. The neurotransmitter 5-HT and B. glabrata neuropeptides FMRFa, buccalin [recognised as AST-A homolog in molluscs [44]] and SK were tested for bioactivity on miracidia. The trajectories of miracidial movement before and after addition of the FMRFa and buccalin peptides $(2 \mu \mathrm{l}$ at $100 \mu \mathrm{M})$ are compared in Figure 3A and 3B. Representative movies can be viewed in Movies S1 and S2. Before addition, miracidia generally swam across the FOV in a direct, linear path (Fig. 3A and 3B - Before). Following application, miracidia showed localized movement within the FOV, as well as increased circular swimming (Fig. 3A and 3B - After). Upon application of buccalin or FMRFa peptides, miracidia within the FOV swam for longer, except for buccalin at $10 \mu \mathrm{M}(P$-value $=0.2964)($ Fig. $3 C)$. The change in acceleration were significant after the addition of 
buccalin or FMRFa (100 $\mu \mathrm{M}$ and $10 \mu \mathrm{M})$ (Fig. 3D). Peptides stimulated a swimming pattern concentrated around the location of the peptides.

In contrast, following application of 5-HT (5 mM; Movie S3), the time within the FOV was insignificant, yet the change of acceleration was significant (File S2). Peptides $(100 \mu \mathrm{M})$ resulted in miracidia staying longer in the region where the peptide was added, but there was no significant change in average velocity, as indicated by two-way ANOVA analysis (File S3). There was also no significant change in the time within FOV, nor in average velocity, upon addition of the SK peptide at 3 different concentrations $(100 \mu \mathrm{M}$, $10 \mu \mathrm{M}$ and $1 \mu \mathrm{M}$; Movie S4). As negative controls, MilliQ water was tested on S. mansomi miracidia and no behavior changes was observed.

\section{Detection of buccalin and FMRFa peptides in B. glabrata- conditioned water}

The B. glabrata buccalin precursor contains numerous buccalin-like peptides (Fig. 4A). The most conserved region in the buccalins is a C-terminal FXGGIG, which following post-translational processing, becomes an amidated peptide. Dot blots performed on conditioned-water extracts from B. glabrata showed the presence of a buccalin-like peptide at dilutions from $10 \mu \mathrm{g}$ to $0.1 \mu \mathrm{g}$ (Fig. 4A). The B. glabrata FMRFa precursor contains numerous FMRF-associated peptides (FaRPs) (Fig. 4B). Following precursor post-translational processing, FaRPs include FMRFa, FLRFa and FIRFa. Dot blots performed on conditioned-water extracts from B. glabrata showed the presence of FaRPs at dilutions from $10 \mu \mathrm{g}$ to 0.1 $\mu \mathrm{g}$ (Fig. 4B).

\section{Characterisation of AST-A and FMRFa receptors}

Sequence comparison of AST-A receptor orthologs between different species was performed to determine conserved structural and functional motifs [45] (Fig. 5A). Both Smp_203500 and BGLB004467 share an NSxxNPxxY motif present within TM7 and putative N-glycosylation ( $\mathrm{N}-\mathrm{x}-\mathrm{T} / \mathrm{s})$ sites within the $\mathrm{N}$-terminal region. In addition, two conserved cysteine residues are potentially important for the function/structure through disulphide bonding between extracellular loop 1 and extracellular loop 2. A comparative analysis of the FMRFa receptor orthologs showed highly conserved TM domains, yet divergent $\mathrm{N}$ - and $\mathrm{C}$ - terminal domains with the exception of $\mathrm{C}$-terminal cysteine residues after TM7 that are required for potential palmitoylation (Fig. 5B).

\section{Discussion}

S. mansoni miracidia respond to snail-derived biomolecules [46], although the precise identity of the active biomolecule(s) has not been clearly defined. One study implicated "miracidia-attracting glycoproteins" present within the snail mucus [12], while in silico analysis from B. glabrata snail conditioned-water proteins predicted interactions of uncharacterized S. mansoni proteins with B. glabrata proteins [46]. Peptides have also been implicated, whereby a snail-derived novel peptide (named P12) stimulated changes in the behaviour of the S. mansoni miracidia [47]. 
In this study, to narrow down biomolecules potentially involved in the parasite and host interplay, we utilised gene resources from both the $B$. glabrata and $S$. mansoni to identify ortholog GPCRs that are likely used by each organism to detect similar ligands. We reported that $8 \mathrm{~S}$. mansoni miracidia GPCRs share significant identity with 8 B. glabrata GPCRs, not only in GO mapping, but also within regions corresponding to putative TM domains. These include GPCRs with similarity to neuropeptide GPCRs that bind FMRFa, AST-A/buccalin and sulfakinin peptides. We propose that the miracidial ortholog GPCRs may be used for neural signaling, requiring a common ligand, and/or are used to detect semiochemical biomolecules present within the water. The latter expectation was validated by miracidial behaviour changes in the presence of snail FMRFamide and AST-A/buccalin peptides.

The AST-A and its receptor have been characterised in various insects [48] where they are involved in multiple functions such as inhibition of juvenile hormone biosynthesis and reduction of food intake [48], AST-A-like neuropeptides have been identified in gastropods and bivalve molluscs, including Lottia gigantea, Theba pisana, Aplysia californica and Crassostrea gigas [49-52]. Buccalin, named following its first identification in the accessory radula closer muscle of $A$. californica [53], has been implicated in various activities in molluscs such as the inhibition of muscle contraction, regulation of feeding and spawning [53-55]. Also in gastropods and bivalves, the AST-A/buccalin receptor was identified through in silico analysis of publicly available genomic datasets including that of $B$. glabrata [56]. In our study, we identified an AST-A/buccalin receptor ortholog in $S$. mansoni, although there are no reports that $S$. mansoni has a buccalin-like peptide. In fact, a comprehensive neuropeptide investigation of 10 platyhelminth species showed that only the free-living turbellarian Macrostomum lignano has a buccalinlike peptide (npp-9 gene; GAYSGFLG) [57]. We identified a buccalin-like peptide in the $B$. glabrata conditioned water. Despite the presence of neuropeptides in mucus secretions having not been well investigated, we previously identified neuropeptides (including buccalin) within the salivary gland mucus of T. pisana $[58,59]$.

The FMRFa was first discovered in the hard clam Mercenaria mercenaria and it is thought to have a pleitropic role in molluscan physiology [60-63]. Extensive studies performed on the freshwater snail Helisoma showed that FMRFa and related peptides are densely concentrated not only in the nervous system but also within the salivary glands [64]. An FMRFa receptor has been identified in the heart and nervous tissue of the land snail Helix $[62,65]$ and the optic lobe membrane of the squid Loligo pelei [66]. The $S$. mansoni genome contains a gene encoding a FLP precursor (npp-13 gene) that may be processed to release two RFamide peptides (HFMPQRFa and YTRFVPQRFa) [57]. A synthetic FLP (GNFFRFa) derived from non-schistosome platyhelminth precursors stimulates contraction of $S$. mansoni muscle fibres in vitro [67]. An FLP receptor has also been reported in the turbellarian flatworm Girardia tigrina based on sequence similarity and a receptor calcium mobilization assay [68]. The homolog receptor in $S$. mansoni miracidia was investigated in the current study due to its similarity with the B. glabrata FMRFa receptor. Our behaviour assays also indicated that snail-derived FMRFa can be detected by $S$. mansoni miracidia due to their staying significantly longer in FOV and the increased acceleration of miracidia, supported by the observed presence of an FLP in B. glabrata conditioned water. However, as S. mansoni 
has the potential to generate endogenous FLPs, we cannot preclude the possibility that the applied FMRFa may stimulate endogenous effects, leading to the observed miracidial behaviour changes.

The monoamine 5-HT plays a critical role in neural transmission and has been very well documented throughout eumetazoans, as has the conservation of 5-HT GPCRs. In adult S. mansoni, 5-HT stimulates motor activity [69], while in the miracidia, an immunofluorescent approach localized 5-HT to within sensory nerves [70]. The 5-HT GPCR was identified within our interspecies GPCR ortholog analysis yet we found that $5-\mathrm{HT}$ at $5 \mathrm{mM}$ did not modify miracidial behaviour, while the significant change in acceleration could be attributed to its high concentration.

Sulfakinin is a sulfated neuropeptide best known for its function as a satiety (food intake) factor [71]. In silico data-mining showed that molluscan SK has the C-terminal RF(W)amide sequence common to insect sulfakinins, as well as the DY motif shared by both insect SKs and vertebrate cholecystokinin (CCK) [72]. Since vertebrate CCKs and insect SKs reveal similar biological function relating to digestive enzyme secretion, satiety and smooth muscle contraction [73], it is possible that their molluscan counterparts have retained similar basic biological activities. In contrast, there is no obvious SK in $S$. mansoni, suggesting that the parasite may only recognize the B. glabrata SK, either as a secreted semiochemical, or once it penetrates the snail as a guidance peptide to navigate to the hepatopancreas where it proliferates [74]. Our behavior assays demonstrated that SK did not alter miracidial behavior (neither the velocity nor duration present under FOV were affected), and therefore it is more likely to act as an internal stimulus in S. mansoni.

FMRFa and buccalin peptides may contribute to a cocktail of biomolecules that could be used as an effective, species-specific attractant. Our serial dilution assays suggested sustained bioactivity for both buccalin and FMRFa peptides at a concentration of at least $1 \mu \mathrm{M}$. We also report 1 orphan peptide GPCR ortholog within B. glabrata and S. mansoni miracida, which is consistent with the possibility that uncharacterized species-specific peptides could help attract miracidia to the appropriate snail host due to its presence in many tissues of B. glabrata and its high expression level in S. mansoni miracidia.

\section{Conclusion}

To minimise transmission and reduce schistosomiasis prevalence, interference with the snail-miracidium interaction is a promising plan of attack. We characterised ortholog GPCRs shared between B. glabrata and S. mansoni miracidia, important biomolecules commonly used for chemosensory communication. The B. glabrata buccalin and FLP GPCRs represented good targets for bioassay, the results from which indicated that buccalin and FMRFa stimulated miracidial behaviour changes, despite the fact that homologs of buccalin-like peptides are not present in S. mansoni. The GPCRs could present as novel targets for the development of anti-helminthic drugs. Chemosensory interaction between miracidia and their hosts could also prove an invaluable model for understanding chemical communication in aquatic environments. 


\section{Abbreviations}

GPCRs

$\mathrm{G}$ protein-coupled receptors

HMMs

Hidden Markov Models

MEGA

Molecular Evolutionary Genetics Analysis

PBS

phosphate buffered saline

PBST

PBS with $0.1 \%$ Tween 20

DAPI

4,6-diamidino-2-phenylindole

PFA

paraformaldehyde

FOV

field of view

serotonin

5-hydroxytryptamine

SK

sulfakinin

CNS

central nervous system

MS

mass spectrometry

USC

University of the Sunshine Coast

QIMR

Queensland Institute of Medical Research Institute.

\section{Declarations}

\section{Funding}

This work was supported by the Australian Research Council (ARC, DP180103694_to SFC, TW, DM). The funders had no role in study design, data collection and analysis, decision to publish, or preparation of the manuscript.

\section{Author contributions}


Conceived and designed the study and supervised the project: SFC and TW. Undertook the study and data analysis: PP, DL, CF, MZ, MD and JB. Contributed to analysis using various tools: DL, MZ and TW. Wrote the paper: PP, DL, RW, KBS, DPM and SFC. All authors read and approved the final version of the manuscript.

\section{Author details}

${ }^{1}$ Faculty of Science, Health and Education, University of the Sunshine Coast, Maroochydore, Queensland 4558, Australia. ${ }^{2}$ Institute of Biochemistry \& Department of Biology, Carleton University, 1125 Colonel By Drive, Ottawa, ON, Canada K1S 5B6. ${ }^{3}$ Molecular Parasitology Laboratory, QIMR Berghofer Medical Research Institute, Brisbane, Q4006, Australia.

\section{Competing interests}

The authors declare that they have no competing interests.

\section{Consent for publication}

Not applicable.

\section{Acknowledgements}

We thank the University of the Sunshine Coast (USC) who provided an internal grant to support this work. We acknowledge the help of Catherine Mainwaring of USC. This research was undertaken with the assistance of resources from the National Computational Infrastructure $(\mathrm{NCl})$, which is supported by the Australian Government. DPM is a National Health and Medical Research Council Leadership Fellow and Senior Scientist at QIMR Berghofer. B. glabrata snails were provided by the NIAID Schistosomiasis Resource Center of the Biomedical Research Institute (Rockville, MD) through NIH-NIAID Contract HHSN272201000005I for distribution through BEI Resources. We acknowledge the Biomphalaria genome consortium that provided an invaluable resource for the gene sequences obtained in this study.

\section{References}

1. McManus DP, Dunne DW, Sacko M, Utzinger J, Vennervald BJ, Zhou XN: Schistosomiasis. Nature reviews Disease primers 2018, 4(1):13.

2. Lozano R, Naghavi M, Foreman K, Lim S, Shibuya K, Aboyans V, Abraham J, Adair T, Aggarwal R, Ahn SY: Global and regional mortality from 235 causes of death for 20 age groups in 1990 and 2010: a systematic analysis for the Global Burden of Disease Study 2010. The Lancet 2013, 380(9859):20952128.

3. Thétiot-Laurent SAL, Boissier J, Robert A, Meunier B: Schistosomiasis chemotherapy. Angewandte Chemie International Edition 2013, 52(31):7936-7956. 
4. Ittiprasert W, Myers J, Odoemelam EC, Raghavan N, Lewis F, Bridger JM, Knight M: Advances in the Genomics and Proteomics of the Freshwater Intermediate Snail Host of Schistosoma mansoni, Biomphalaria glabrata. In: Biomphalaria Snails and Larval Trematodes. edn.: Springer; 2011: 191213.

5. Berriman M, Haas BJ, LoVerde PT, Wilson RA, Dillon GP, Cerqueira GC, Mashiyama ST, Al-Lazikani B, Andrade LF, Ashton PD et al: The genome of the blood fluke Schistosoma mansoni. Nature 2009, 460(7253):352-358.

6. Adema CM, Hillier LW, Jones CS, Loker ES, Knight M, Minx P, Oliveira G, Raghavan N, Shedlock A, do Amaral LR et al: Whole genome analysis of a schistosomiasis-transmitting freshwater snail. Nature communications 2017, 8:15451-15451.

7. Haberl B, Kalbe M, Fuchs H, Ströbel M, Schmalfuss G, Haas W: Schistosoma mansoni and S. haematobium: Miracidial host-finding behaviour is stimulated by macromolecules. International Journal for Parasitology 1995, 25(5):551-560.

8. Haas W, Gui M, Haberl B, Strobel M: Miracidia of Schistosoma japonicum: approach and attachment to the snail host. The Journal of parasitology 1991, 77(4):509-513.

9. Sobhon P, Upatham ES: Snail hosts, life-cycle, and tegumental structure of oriental schistosomes. Snail hosts, life-cycle, and tegumental structure of oriental schistosomes 1990.

10. Boissier $\mathrm{J}$, Mone H: Male-female larval interactions in Schistosoma mansoni-infected Biomphalaria glabrata. Int J Parasitol 2001, 31(4):352-358.

11. Campos TD, Young ND, Korhonen PK, Hall RS, Mangiola S, Lonie A, Gasser RB: Identification of G protein-coupled receptors in Schistosoma haematobium and S. mansoni by comparative genomics. Parasit Vectors 2014, 7:242.

12. Kalbe M, Haberl B, Haas W: Snail host finding by Fasciola hepatica and Trichobilharzia ocellata: compound analysis of "miracidia-attracting glycoproteins". Experimental parasitology 2000, 96(4):231-242.

13. Chaisson KE, Hallem EA: Chemosensory behaviors of parasites. Trends in parasitology 2012, 28(10):427-436.

14. Hertel J, Holweg A, Haberl B, Kalbe M, Haas W: Snail odour-clouds: spreading and contribution to the transmission success of Trichobilharzia ocellata (Trematoda, Digenea) miracidia. Oecologia 2006, 147(1):173-180.

15. Sakmar TP: Rhodopsin: a prototypical G protein-coupled receptor. Progress in nucleic acid research and molecular biology 1998, 59:1-34.

16. Doty RL: Handbook of Olfaction and Gustation: Wiley; 2015.

17. Fitzpatrick JM, Peak E, Perally S, Chalmers IW, Barrett J, Yoshino TP, Ivens AC, Hoffmann KF: Antischistosomal intervention targets identified by lifecycle transcriptomic analyses. PLoS neglected tropical diseases 2009, 3(11):e543.

18. Taft AS, Norante FA, Yoshino TP: The identification of inhibitors of Schistosoma mansoni miracidial transformation by incorporating a medium-throughput small-molecule screen. Experimental 
parasitology 2010, 125(2):84-94.

19. Hoffmann KF, Davis EM, Fischer ER, Wynn TA: The guanine protein coupled receptor hodopsin is developmentally regulated in the free-living stages of Schistosoma mansoni. Molecular and biochemical parasitology 2001, 112(1):113-123.

20. Dissous $C$, Morel $M$, Vanderstraete $M$ : Venus kinase receptors: prospects in signaling and biological functions of these invertebrate kinases. Front Endocrinol (Lausanne) 2014, 5:72.

21. Consortium SjGSaFA: The Schistosoma japonicum genome reveals features of host-parasite interplay. Nature 2009, 460(7253):345-351.

22. El-Shehabi F, Vermeire JJ, Yoshino TP, Ribeiro P: Developmental expression analysis and immunolocalization of a biogenic amine receptor in Schistosoma mansoni. Experimental parasitology 2009, 122(1):17-27.

23. El-Shehabi F, Taman A, Moali LS, El-Sakkary N, Ribeiro P: A novel G protein-coupled receptor of Schistosoma mansoni (SmGPR-3) is activated by dopamine and is widely expressed in the nervous system. PLoS neglected tropical diseases 2012, 6(2):e1523.

24. Liang D, Zhao M, Wang T, McManus DP, Cummins SF: GPCR and IR genes in Schistosoma mansoni miracidia. Parasit Vectors 2016, 9(1):563.

25. Zamanian M, Kimber MJ, McVeigh P, Carlson SA, Maule AG, Day TA: The repertoire of G proteincoupled receptors in the human parasite Schistosoma mansoni and the model organism Schmidtea mediterranea. BMC genomics 2011, 12:596.

26. Mason PR, Fripp PJ: The reactions of Schistosoma mansoni miracidia to light. The Journal of parasitology 1977, 63(2):240-244.

27. Short RB, Gagne HT: Fine structure of possible photoreceptor in cercariae of Schistosoma mansoni. The Journal of parasitology 1975, 61(1):69-74.

28. Lewis FA, Patterson CN, Knight M, Richards CS: The relationship between Schistosoma mansoni and Biomphalaria glabrata: genetic and molecular approaches. Parasitology 2001, 123 Suppl:S169-179.

29. Sandland GJ, Foster AV, Zavodna M, Minchella DJ: Interplay between host genetic variation and parasite transmission in the Biomphalaria glabrata-Schistosoma mansoni system. Parasitol Res 2007, 101(4):1083-1089.

30. Zavodna M, Sandland GJ, Minchella DJ: Effects of intermediate host genetic background on parasite transmission dynamics: a case study using Schistosoma mansoni. Experimental parasitology 2008, 120(1):57-61.

31. Roger E, Gourbal B, Grunau C, Pierce RJ, Galinier R, Mitta G: Expression analysis of highly polymorphic mucin proteins (Sm PoMuc) from the parasite Schistosoma mansoni. Molecular and biochemical parasitology 2008, 157(2):217-227.

32. Raghavan N, Tettelin H, Miller A, Hostetler J, Tallon L, Knight M: Nimbus (Bgl): an active non-LTR retrotransposon of the Schistosoma mansoni snail host Biomphalaria glabrata. Int J Parasito/2007, 37(12):1307-1318. 
33. Toledo R, Fried B: Biomphalaria Snails and Larval Trematodes: Springer New York; 2010.

34. Wang T, Zhao M, Rotgans BA, Strong A, Liang D, Ni G, Limpanont Y, Ramasoota P, McManus DP, Cummins SF: Proteomic Analysis of the Schistosoma mansoni Miracidium. PLoS One 2016, 11(1): 00147247.

35. Haas BJ, Papanicolaou A, Yassour M, Grabherr M, Blood PD, Bowden J, Couger MB, Eccles D, Li B, Lieber $\mathrm{M}$ et al: De novo transcript sequence reconstruction from RNA-seq using the Trinity platform for reference generation and analysis. Nature Protocols 2013, 8(8):1494-1512.

36. Grabherr MG, Haas BJ, Yassour M, Levin JZ, Thompson DA, Amit I, Adiconis X, Fan L, Raychowdhury $\mathrm{R}$, Zeng $\mathrm{Q}$ et al: Full-length transcriptome assembly from RNA-Seq data without a reference genome. Nat Biotechno/ 2011, 29(7):644-652.

37. Mortazavi A, Williams BA, McCue K, Schaeffer L, Wold B: Mapping and quantifying mammalian transcriptomes by RNA-Seq. Nature Methods 2008, 5(7):621-628.

38. Kumar S, Stecher G, Peterson D, Tamura K: MEGA-CC: computing core of molecular evolutionary genetics analysis program for automated and iterative data analysis. Bioinformatics 2012, 28(20):2685-2686.

39. Edgar RC: MUSCLE: multiple sequence alignment with high accuracy and high throughput. Nucleic acids research 2004, 32(5):1792-1797.

40. Götz S, García-Gómez JM, Terol J, Williams TD, Nagaraj SH, Nueda MJ, Robles M, Talón M, Dopazo $\mathrm{J}$, Conesa A: High-throughput functional annotation and data mining with the Blast2GO suite. Nucleic Acids Research 2008, 36(10):3420-3435.

41. Letunic I, Bork P: Interactive Tree Of Life (iTOL) v5: an online tool for phylogenetic tree display and annotation. Nucleic Acids Research 2021.

42. Fujikoshi Y: Two-way ANOVA models with unbalanced data. Discrete Mathematics 1993, 116(1):315334.

43. Adamson KJ, Wang T, Rotgans B, Kruangkum T, Kuballa AV, Storey KB, Cummins SF: Genes and associated peptides involved with aestivation in a land snail. Gen Comp Endocrinol 2015.

44. Li Z, Cardoso JCR, Peng M, Inácio JPS, Power DM: Evolution and Potential Function in Molluscs of Neuropeptide and Receptor Homologues of the Insect Allatostatins. 2021, 12(1120).

45. Felix RC, Trindade M, Pires IR, Fonseca VG, Martins RS, Silveira H, Power DM, Cardoso JC: Unravelling the Evolution of the Allatostatin-Type A, KISS and Galanin Peptide-Receptor Gene Families in Bilaterians: Insights from Anopheles Mosquitoes. PloS one 2015, 10(7):e0130347.

46. Fogarty CE, Zhao M, McManus DP, Duke MG, Cummins SF, Wang T: Comparative study of excretorysecretory proteins released by Schistosoma mansoni-resistant, susceptible and naïve Biomphalaria glabrata. Parasit Vectors 2019, 12(1):452-452.

47. Wang T, Wyeth RC, Liang D, Bose U, Ni G, McManus DP, Cummins SF: A Biomphalaria glabrata peptide that stimulates significant behaviour modifications in aquatic free-living Schistosoma mansoni miracidia. PLoS Neg/ Trop Dis 2019, 13(1):e0006948. 
48. Stay B, Tobe SS: The role of allatostatins in juvenile hormone synthesis in insects and crustaceans. Annu Rev Entomol 2007, 52:277-299.

49. Adamson KJ, Wang T, Zhao M, Bell F, Kuballa AV, Storey KB, Cummins SF: Molecular insights into land snail neuropeptides through transcriptome and comparative gene analysis. $B M C$ genomics $2015,16: 308$.

50. Veenstra JA: Neurohormones and neuropeptides encoded by the genome of Lottia gigantea, with reference to other mollusks and insects. Gen Comp Endocrino/ 2010, 167(1):86-103.

51. Bauknecht P, Jekely G: Large-Scale Combinatorial Deorphanization of Platynereis Neuropeptide GPCRs. Cell Rep 2015, 12(4):684-693.

52. Stewart MJ, Favrel P, Rotgans BA, Wang T, Zhao M, Sohail M, O'Connor WA, Elizur A, Henry J, Cummins SF: Neuropeptides encoded by the genomes of the Akoya pearl oyster Pinctata fucata and Pacific oyster Crassostrea gigas: a bioinformatic and peptidomic survey. BMC genomics 2014, 15(1):840.

53. Cropper EC, Miller MW, Tenenbaum R, Kolks MA, Kupfermann I, Weiss KR: Structure and action of buccalin: a modulatory neuropeptide localized to an identified small cardioactive peptide-containing cholinergic motor neuron of Aplysia californica. Proceedings of the National Academy of Sciences of the United States of America 1988, 85(16):6177-6181.

54. Van In V, Ntalamagka N, O'Connor W, Wang T, Powell D, Cummins SF, Elizur A: Reproductive neuropeptides that stimulate spawning in the Sydney Rock Oyster (Saccostrea glomerata). Peptides 2016, 82:109-119.

55. Miller MW, Beushausen S, Cropper EC, Eisinger K, Stamm S, Vilim FS, Vitek A, Zajc A, Kupfermann I, Brosius $\mathrm{J}$ et al: The buccalin-related neuropeptides: isolation and characterization of an Aplysia cDNA clone encoding a family of peptide cotransmitters. The Journal of neuroscience : the official journal of the Society for Neuroscience 1993, 13(8):3346-3357.

56. Cardoso JC, Félix RC, Bjärnmark N, Power DM: Allatostatin-type A, kisspeptin and galanin GPCRs and putative ligands as candidate regulatory factors of mantle function. Marine genomics 2016, 27:2535 .

57. McVeigh P, Mair GR, Atkinson L, Ladurner P, Zamanian M, Novozhilova E, Marks NJ, Day TA, Maule AG: Discovery of multiple neuropeptide families in the phylum Platyhelminthes. Int J Parasitol 2009, 39(11):1243-1252.

58. Adamson KJ, Wang T, Rotgans BA, Kuballa AV, Storey KB, Cummins SF: Differential peptide expression in the central nervous system of the land snail Theba pisana, between active and aestivated. Peptides 2016, 80:61-71.

59. Stewart MJ, Wang T, Koene JM, Storey KB, Cummins SF: A "Love" Dart Allohormone Identified in the Mucous Glands of Hermaphroditic Land Snails. The Journal of biological chemistry 2016, 291(15):7938-7950.

60. Lopez-Vera E, Aguilar MB, Heimer de la Cotera EP: FMRFamide and related peptides in the phylum mollusca. Peptides 2008, 29(2):310-317. 
61. Price DA, Greenberg MJ: Structure of a molluscan cardioexcitatory neuropeptide. Science 1977, 197(4304):670-671.

62. Payza K: FMRFamide receptors in Helix aspersa. Peptides 1987, 8(6):1065-1074.

63. Voigt KH, Kiehling C, Frosch D, Schiebe M, Martin R: Enkephalin-related peptides: direct action on the octopus heart. Neurosci Lett 1981, 27(1):25-30.

64. Bulloch AG, Price DA, Murphy AD, Lee TD, Bowes HN: FMRFamide peptides in Helisoma: identification and physiological actions at a peripheral synapse. The Journal of neuroscience : the official journal of the Society for Neuroscience 1988, 8(9):3459-3469.

65. Payza K, Greenberg MJ, Price DA: Further characterization of Helix FMRFamide receptors: kinetics, tissue distribution, and interactions with the endogenous heptapeptides. Peptides 1989, 10(3):657661.

66. Chin GJ, Payza K, Price DA, Greenberg MJ, Doble KE: Characterization and solubilization of the FMRFamide receptor of squid. The Biological bulletin 1994, 187(2):185-199.

67. Day TA, Maule AG, Shaw C, Halton DW, Moore S, Bennett JL, Pax RA: Platyhelminth FMRFamiderelated peptides (FaRPs) contract Schistosoma mansoni (Trematoda: Digenea) muscle fibres in vitro. Parasitology 1994, 109 ( Pt 4):455-459.

68. Omar HH, Humphries JE, Larsen MJ, Kubiak TM, Geary TG, Maule AG, Kimber MJ, Day TA: Identification of a platyhelminth neuropeptide receptor. Int J Parasito/ 2007, 37(7):725-733.

69. Barker LR, Bueding E, Timms AR: The possible role of acetylcholine in Schistosoma mansoni. $\mathrm{Br} J$ Pharmacol Chemother 1966, 26(3):656-665.

70. Jones BR, Pan SC, Amarin MM: Structure of "Sensory" Nerves and Serotonin-Like Immunofluorescent Activity in Schistosoma Mansoni Miracidia and Cercariae. In: Biodeterioration Research 2. edn.: Springer; 1989: 601-626.

71. Wicher D, Derst C, Gautier H, Lapied B, Heinemann S, Agricola H-j: The satiety signaling neuropeptide perisulfakinin inhibits the activity of central neurons promoting general activity. 2007, 1(3).

72. Zatylny-Gaudin C, Favrel P: Diversity of the RFamide Peptide Family in Mollusks. 2014, 5(178).

73. Nachman RJ, Giard W, Favrel P, Suresh T, Sreekumar S, Holman GM: Insect Myosuppressins and Sulfakinins Stimulate Release of the Digestive Enzyme a-Amylase in Two Invertebrates: The Scallop Pecten maximus and Insect Rhynchophorus ferrugineus. Annals of the New York Academy of Sciences 1997, 814(1):335-338.

74. Gérard $C$, Moné $H$, Théron A: Schistosoma mansoni - Biomphalaria glabrata: dynamics of the sporocyst population in relation to the miracidial dose and the host size. Canadian Journal of Zoology 1993, 71(9):1880-1885.

\section{Figures}




\section{S. mansoni}

\section{B. glabrata}

\section{Transcriptome protein models}

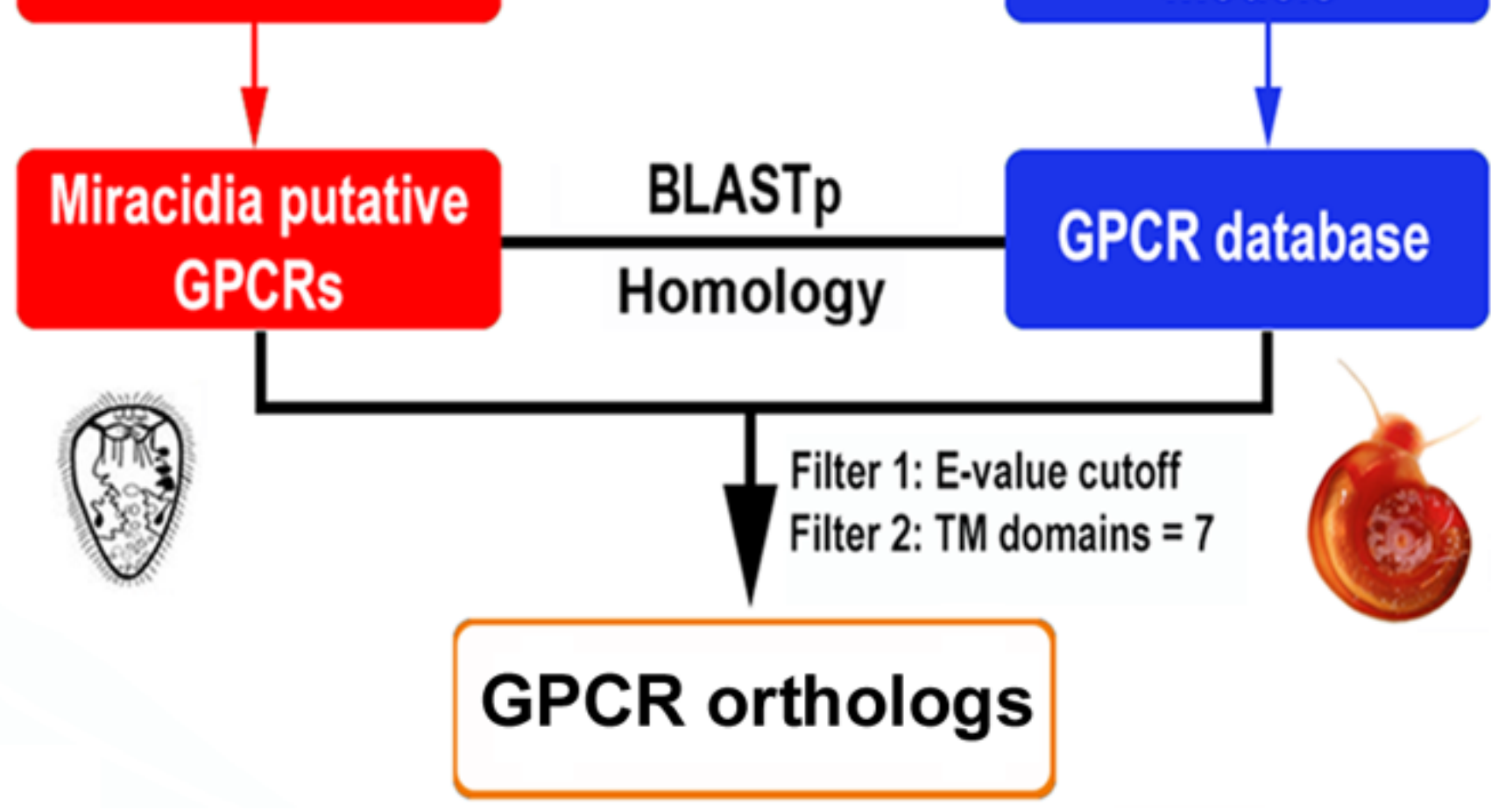

Figure 1

Workflow for identification of shared GPCRs mined from the B. glabrata genome and transcriptome of $S$. mansoni miracidia.

Figure 2

Characterization of GPCR orthologs shared between B. glabrata and S. mansoni miracidia. (A) Phylogenetic tree analysis of shared GPCRs, where each B. glabrata GPCR clusters with an ortholog receptor from S. mansoni. Bootstrap values support the confidence levels of clades. (B) Heatmap showing expression of shared GPCR- (in TPM) encoding genes in S. mansoni miracidia at $6 \mathrm{~h}$ post-hatch and different B. glabrata tissues.

Figure 3 
Miracidial behaviour assay using buccalin and FMRFa peptides. (A) Representative trajectories of miracidial movement before and after the addition of the buccalin solution $(100 \mu \mathrm{M})$ to the center of the recording area. Each colour represents one indistinguishable miracidium individual. See Movie S1 for representative assay video. (B) Representative trajectories of miracidia movement before and after the addition of the FMRFa solution $(100 \mu \mathrm{M})$ to the center of the area. Each colour represents one indistinguishable miracidium individual. See Movie S2 for representative assay video. (C) Graph of time duration of miracidia remaining in the videoing zone, and (D) mean acceleration values, before and after the addition of buccalin and FMRFa.

\section{Figure 4}

Biomphalaria glabrata precursor sequence and dot blot assay for buccalin and FMRFa in B. glabrataconditioned water. (A) Buccalin, and (B) FMRFa. For neuropeptide precursor sequence, yellow - signal peptide, red - putative cleavage sites, green - amidation, grey - bioactive peptides.

\section{Figure 5}

Comparisons of B. glabrata and S. mansoni buccalin/allatostatin-A and FMRFa receptors with orthologs of other species. Comparative amino acid alignment of (A) allatostatin-A/buccalin and (B) FMRFa receptors. Identical amino acids are highlighted in blue. Seven potential TM spanning domains were identified by TMHMM and are indicated by TM1-7. Predicted N-glycosylation sites are underlined in red. Two conserved cysteine residues are annotated with green asterisks. The characteristic conserved cysteine residue after TM7 is indicated by a green circle. Accession numbers of receptor genes are available in File S1c

\section{Supplementary Files}

This is a list of supplementary files associated with this preprint. Click to download.

- FileS1.xlsx

- Files2.tif

- Files3.tif

- LegendforAdditionalsupplementaryfiles.docx

- LegendforSupplementarymovies.docx

- MovieS1.avi

- MovieS2.avi

- MovieS3.avi 
- Movies4.avi

Page 21/21 